\title{
A Comparative Study Using Two SEM Techniques on Different Samples Sizes for Determining Factors of Older Employee's Motivation and Satisfaction
}

\author{
Maja Rožman *, Polona Tominc and Borut Milfelner \\ Faculty of Economics and Business, University of Maribor, 2000 Maribor, Slovenia; polona.tominc@um.si (P.T.); \\ borut.milfelner@um.si (B.M.) \\ * Correspondence: maja.rozman1@um.si
}

Received: 6 February 2020; Accepted: 9 March 2020; Published: 12 March 2020

check for updates

\begin{abstract}
The purpose of this article is to present the relationships among older employee stress, motivation, satisfaction, and relationships in the workplace using two different approaches and different sample sizes. Research was implemented on an initial sample of 1013 older employees. In the next step, six smaller samples were calculated using the random selection of cases, namely samples with $25,50,100,250,400$, and 500 older employees. This way the possible impact of sample size on relationships between latent variables using the covariance-based structural equation modeling (CB-SEM) and the partial least squares structural equation modeling (PLS-SEM) methods was assessed. The results on the larger samples have proved to be quite robust since they were confirmed with both approaches. They indicate that stress has a strong and negative impact on employee relationships and also a negative impact on employee satisfaction. Furthermore, employee relationships have a strong and positive impact on satisfaction and a positive impact on employee motivation. In addition, satisfaction has a strong and positive impact on employee motivation. The present paper helps readers to better understand the difference between the CB-SEM and the PLS-SEM methods. Researchers should be encouraged to use both techniques, even though CB-SEM methods have had a long tradition in management and marketing research since both fields heavily rely on psychometric measurement. From the organizational point of view, conclusions highlight the importance of the impact the variables of older employee stress, motivation, satisfaction and employee relations have on each other in the workplace.
\end{abstract}

Keywords: stress; employee motivation; employee satisfaction; employee relations

\section{Introduction}

The aging of the population is one of the most important social and economic challenges in Europe for the next several decades. Companies need to adapt to the changing characteristics of an aging workforce [1]. Due to an increase in the number of older employees in the near future, companies have to pay more attention to the current situation of older people. At present, research about older employees is limited.

Additionally, research dealing with problems concerning the relationships between latent variables are frequently conducted within micro and small companies, where small samples can present a challenge when applying regression models. In such instances, the information about differences in results when applying methods can be of particular importance for the researches who seek guidelines for applying the right method of structural equation modeling (SEM).

The structural equation model allows the simultaneous modeling of relationships among multiple endogenous and exogenous variables [2]. The covariance-based SEM (CB-SEM) and partial least squares 
SEM (PLS-SEM) are two common approaches to structural equation modeling. The performance of CB-SEM and PLS-SEM for small sample sizes when distributions are not normal [3-5] has been debated many times because for normal distributions, CB-SEM estimates were found to be inaccurate for small sample size, while PLS-SEM could produce the path estimates. Meanwhile, for a larger sample size, CB-SEM estimates have lower variability when compared to PLS-SEM. Under nonnormality, CB-SEM path estimates were inaccurate for a small sample size [5].

For our study, the relationships among older employee stress, motivation, satisfaction, and relationships in the workplace using two different approaches (CB-SEM and PLS-SEM) and different sample sizes were investigated. There is not much literature and research that is comprehensively based on theoretical knowledge nor studies about older employees and the four investigated concepts. Some studies on a sample of 1649 U.S. older workers [6] of the relationships between co-worker support, supervisor support, job stress, and presenteeism suggest that presenteeism was low and job stress was moderate when co-worker and supervisor support were high. Furthermore, job stress had a significant and direct positive effect on presenteeism, co-worker support had significant direct negative effects on presenteeism and job stress. Supervisor support had an insignificant effect on presenteeism but a significant negative effect on job stress. Co-worker support and supervisor support were highly correlated, therefore good and positive employee relations are very important. The authors' findings lead to the conclusion that older employees in the U.S. have good relationships with their colleagues and supervisors and they work in more supportive work environments, which leads to better health. Further findings $[7,8]$ indicate that there is a positive relationship between job satisfaction, job motivation, and job performance. Research according to [8] show that employee satisfaction has a positive impact on employee motivation, which means that employee satisfaction is associated with a motivation to share knowledge. Therefore, employers should promote effective knowledge sharing in age-diverse organizations.

According to our knowledge, only scarce evidence exists in the literature concerning the use of different methodological approaches, generally in the field of human resource management or internal marketing. This is mostly relevant when researchers are dealing with smaller numbers of employees in the sample and when the distribution of their answers is not normal. Concerning this research gap, the main goal of this paper is to provide theoretical, methodological, and practical implications concerning the four research constructs. Therefore, our contributions to the field are twofold. First, the results of the study can help academics and managers to understand better how stress and employee relations can impact work motivation and satisfaction. Second, it is important for researchers to have more information on how the number of cases included in the research can influence research results gained through different research methods.

Research was implemented on an initial sample of 1013 older employees. In the next step, six smaller samples were calculated using the random selection of cases, namely samples with 25 , $50,100,250,400$, and 500 units, because we want to check the possible impact of sample size on relationships between the latent variables using the CB-SEM and the PLS-SEM methods. According to $[9,10]$, structural equation modeling is a multivariate analysis technique that is widely used in the social sciences and it can be used for the analysis of simple relationships between variables or complex analyses of measurement equivalence for first- and higher-order constructs. Due to its flexible framework for developing and analyzing complex relationships among different variables, it allows researchers to test the validity of theory using empirical models [11]. Thus, Ref. [12] emphasizes that structural equation modeling has become "a quasi-standard in marketing and management research when it comes to analyzing the cause-effect relations between latent constructs".

In recent years, structural equation modeling as an analytical approach that simultaneously combines factor analysis and linear regression models for theory testing has been used for a large segment of management research. With this approach, latent variables (factors) represent the concepts of a theory, and data from measures (indicators) are used as input for statistical analyses that provide evidence about the relationships among latent variables [13]. 
There are two types of SEM: covariance-based SEM (CB-SEM) and partial least squares SEM (PLS-SEM). Some of the most common software used for CB-SEM are LISREL, AMOS, EQS, and MPLUS. PLS path modeling software includes SmartPLS and PLS-Graph [5].

\section{Materials and Methods}

\subsection{Conceptual Model and Hypotheses}

Where employees are stressed, negative results can show in terms of the communication and relationships among them. Those who are stressed can be angry and irritable, which-together with low levels of morale, satisfaction, and motivation-can have negative impacts on team dynamics, communication within the company, and internal relationships $[14,15]$. Therefore, the following hypothesis is proposed:

Hypothesis 1 (H1). Occupational stress has a negative impact on employee relations.

Many studies have suggested that low levels of employee satisfaction caused by occupational stress can lead to increases in absenteeism, presenteeism, employee turnover, and also to decreases in productivity and performance in the workplace (see e.g., [14,16,17]). Additionally, Refs. [18,19] emphasize that occupational stress can lead to physical, mental, and emotional exhaustion as well as an increased rate of burnout, absenteeism, and employee turnover. Employees with a higher level of occupational stress may not be satisfied with their working conditions or their job, therefore they will not feel happy working in the company [16]. The higher level of occupational stress causes less employee satisfaction [20] and also causes poorer relationships among colleagues [21]. Hence, it is proposed:

Hypothesis 2 (H2). Occupational stress has a negative impact on employee satisfaction.

Good relationships in the workplace lead to an increased level of satisfaction among the employees and in turn lead to an increase in productivity [22]. Employee satisfaction refers to an employee's satisfaction with the general work characteristics, and it affects the morale of employees. It also relates to the expectations of an employee on the job and the degree of happiness derived from the condition of service [23]. According to this, the following hypothesis is proposed:

Hypothesis 3 (H3). Favorable employee relations have a positive impact on employee satisfaction.

Positive interactions and healthy relationships in the workplace increase good feelings and morale, improve work, and motivate employees. Therefore, favorable employee relations have an impact on employee motivation (see e.g., [14,21,24]). In addition, favorable and positive relationships and interactions at work improve work satisfaction, which leads to a high level of work motivation [24]. Hence, it is proposed:

Hypothesis 4 (H4). Favorable employee relations have a positive impact on employee motivation.

According to previous research, there is a positive connection between employee satisfaction and motivation (see e.g., [23,25]). Dissatisfied employees can negatively affect a company because they have a lack of work motivation that can have negative effects on productivity. Thus, employee satisfaction has a positive and statistically significant impact on employee motivation [26]. Employers who take the time to understand the reasons for the dissatisfaction of employees can often find the right solutions to turn unhappy employees into motivated ones [23]. Therefore, it is hypothesized:

Hypothesis 5 (H5). Employee satisfaction has a positive impact on employee motivation. 
According to the above hypothesis, the conceptual model presented in Figure 1 was proposed.

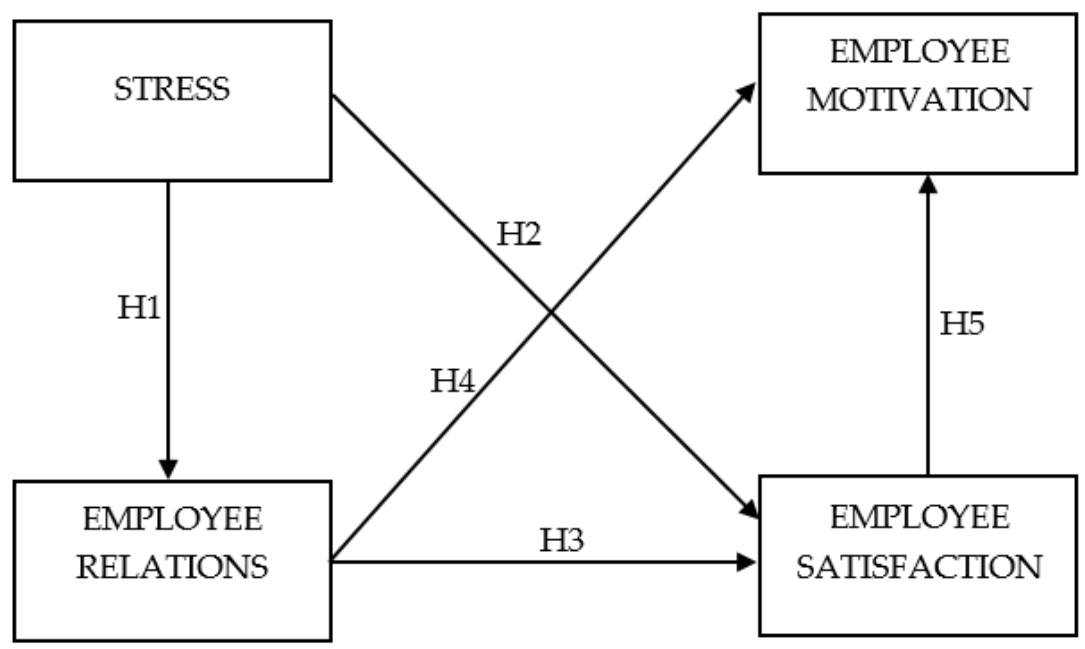

Figure 1. Conceptual model and hypotheses.

\subsection{Sample Characteristics}

An empirical study was deployed on the sample of older employees (from 50 to 65 years of age) in 1000 large- and medium-sized companies in Slovenia. The companies were randomly selected. The main research involved 472 large- and medium-sized companies, as the response rate was $47.2 \%$. In each company, up to four older employees were selected to participate in the research. The final sample consisted of 1013 older workers who responded to the questionnaire.

The sample consisted of $38.4 \%$ workers from ages 50 to 55 years, $42.0 \%$ from ages 56 to 61 years, and $19.0 \%$ from ages 62 to 67 . Only $0.6 \%$ of them were over 68 years old. The biggest share of companies were large companies (54.8\%). Medium-sized companies comprised $45.2 \%$. Concerning the industry types, the companies were from manufacturing (31.1\%); trade, maintenance, and repair of motor vehicles (15.2\%); financial and insurance activities $(11.2 \%)$; professional, scientific, and technical activities (11.4\%); information and communication activities (7.7\%); construction (4.3\%); other diversified business activities (3.4\%); real estate business (3.4\%); catering (2.7\%); health and social care (2.2\%); supply of electricity, gas, and steam (2.3\%); transport and storage (1.8\%); agriculture and hunting, forestry, fishing (1.2\%); water supply, sewage, and waste management, environmental rehabilitation (1.1\%); other activities $(0.6 \%)$; and mining $(0.4 \%)$.

\subsection{Data Collection Method}

The questionnaire was addressed to the owner/manager of the company and sent via e-mail or ordinary post (depending on the availability of contact data). The owner/manager of the company was asked to distribute a questionnaire among older employees. To increase the response rate, reminders to complete the questionnaire were sent by e-mail and by contacting them personally in the company.

\subsection{Measurement Instrument}

The questionnaire included questions of a closed type. The respondents indicated their agreement with the listed statements on a five-point Likert-type scale, where $1=$ strongly disagree and $5=$ completely agree. Items for the employee motivation were adopted from [27], items for stress were adopted from [19], items for the employee relations from [28], and items for work satisfaction from [29]. Due to the back-translation procedure and some updated expressions, some wording in the scales were changed. 


\subsection{Samples Calculation}

From the initial sample of 1013 older employees, six smaller samples were calculated using the random selection of cases, namely samples with $25,50,100,250,400$, and 500 units. This was performed in order to check the possible impact of sample size on relationships between latent variables using the CB-SEM and the PLS-SEM method.

\subsection{Structural Equation Modeling with PLS-SEM}

PLS-SEM can relate the set of independent variables to multiple dependent variables and it can also handle many independent variables even when predictors display multicollinearity $[3,4]$. As already mentioned in the paper, PLS-SEM may be implemented as a regression model, predicting one or more dependents from a set of one or more independents; or it can be implemented as a path model, handling causal paths relating predictors as well as paths relating the predictors to the response variable(s). In addition, data characteristics such as minimum sample size, nonnormal data, and scale of measurement (i.e., the use of different scale types) are among the most often stated reasons for applying PLS-SEM [30]. Moreover, the minimum sample size will ensure that the results of the statistical method are robust and the model is generalizable. An insufficient sample size may lead to PLS-SEM results that highly differ from those of another sample [3]. According to [4], the most prevalent implementation as a path model is SmartPLS.

The advantages of PLS include the ability to model multiple dependents as well as multiple independents; the ability to handle multicollinearity among the independents; having robustness in the face of data noise and missing data; and creating independent latent variables directly on the basis of cross-products involving the response variable(s), which makes for stronger predictions [4]. PLS-SEM has a major advantage because it always produces a single specific (determinate) score for each composite for each observation, once the weights are established. These determinate scores are proxies of the concepts being measured, just as factors are proxies for the conceptual variables in CB-SEM [31]. Using these proxies as an input, PLS-SEM applies ordinary least squares regression with the objective of minimizing the error terms (the residual variance) of the endogenous constructs. Thus, PLS-SEM estimates coefficients (path model relationships) that maximize the $R^{2}$ values of the endogenous constructs. The prediction objectives of PLS-SEM are achieved with this feature. The preferred method, when the research objectives are theory development and explanation of variance (prediction of the constructs), is therefore PLS-SEM. Moreover, PLS-SEM is regarded as a variance-based approach to SEM [3].

PLS has some disadvantages that include greater difficulty of interpreting the loadings of the independent latent variables (which are based on cross-product relations with the response variables, not based, as in common factor analysis, on covariances among the manifest independents) and unknown distributional properties of estimates that do not allow the researcher to assess significance except through a bootstrap induction [4].

\subsection{Structural Equation Modeling with CB-SEM}

CB-SEM develops a theoretical covariance matrix based on a specified set of structural equations; this technique focuses on estimating a set of model parameters in such a way that the difference between the theoretical covariance matrix and the estimated covariance matrix is minimized [12,32]. According to [33], CB-SEM usually involves a maximum likelihood procedure whose goal is to minimize the difference between the observed and the estimated covariance matrices, as opposed to maximizing explained variance.

When using CB-SEM, structural models can be complex and interactive effects can be assessed. When CB-SEM is executed, the error terms are modeled for each indicator and the loadings of the individual indicator are obtained. This enables the elimination of indicators with large error terms and/or low loadings, thus improving the quality of the latent constructs modeled. Specifically, the 
confirmatory factor analysis stage of CB-SEM allows all latent constructs to covary mutually and thereby permits the quantitative assessment of both convergent and discriminant validity for each construct [33,34].

The CB-SEM model estimation requires a set of assumptions to be fulfilled, including the multivariate normality of data and a minimum sample size. If CB-SEM assumptions cannot be met or the research objective offers a prediction rather than a confirmation of structural relationships, then the variance-based PLS-SEM is the preferred method [12]. In comparison with CB-SEM results, which can be highly imprecise when the assumptions are violated, PLS-SEM often provides more robust estimations of the structural model [35].

The disadvantages of CB-SEM are as follows: when using CB-SEM, initially hypothesized models almost always exhibit inadequate fit. In response, researchers should reject the model and reconsider the study (which usually requires gathering new data), particularly when many variables must be deleted to achieve fit [12]. Additionally, CB-SEM requires a set of stringent assumptions such as the normality of data and an adequate sample size. When these assumptions for CB-SEM are not met, the alternative approach of PLS-SEM is used [5].

\subsection{PLS-SEM Compared with CB-SEM}

According to [33], when assessing the quality of a structural model, CB-SEM and PLS-SEM use different approaches. CB-SEM often eliminates relevant indicator variables, thereby reducing the validity of constructs, while PLS-SEM creates composite constructs that generally include additional theory-based indicator variables while still optimizing predictive accuracy and relevance [32]. Ref. [33] has also argued that PLS-SEM analyses can easily incorporate single-item measures and can obtain solutions to much more highly complex models, i.e., models with a large number of constructs, indicators, and structural relationships. According to [12], CB-SEM is an appropriate method when the research objective is theory testing and confirmation. By contrast, when the research objective is prediction and theory development, then the appropriate method is PLS-SEM.

Since there are many different types of distributions (e.g., normal, binomial, Poisson), researchers working with SEM generally only need to distinguish normal from nonnormal distributions. Normal distributions are usually desirable, especially when working with CB-SEM. By contrast, PLS-SEM generally makes no assumptions about data distributions [3].

CB-SEM considers the constructs common factors that explain the covariation among its associated indicators. The scores of these common factors are neither known nor needed in the estimation of model parameters. On the other hand, PLS-SEM uses proxies to represent the constructs of interest, which are weighted composites of indicator variables for a particular construct.

Rules of thumb for choosing between PLS-SEM and CB-SEM [12] are to use PLS-SEM when (a) the goal is predicting key target constructs or identifying key "driver" constructs, (b) formatively measured constructs are part of the structural model, (c) the structural model is complex (having many constructs and many indicators), (c) the sample size is small and/or the data are nonnormally distributed, and (d) the plan is to use latent variable scores in subsequent analyses.

Ref. [12], on the other hand, suggest using CB-SEM when (a) the goal is theory testing, theory confirmation, or the comparison of alternative theories; (b) error terms require additional specification, such as the covariation; (c) the structural model has circular relationships; and (d) the research requires a global goodness of fit criterion.

\subsection{Data Processing Methods}

In the first phase of data processing, the confirmatory factor analysis (CFA) was used in order to test the dimensionality of constructs and to establish convergent and discriminant validity. The composite reliability (CR) measure was used for testing reliability, and average variance extracted (AVE) for testing convergent validity. Discriminant validity was assessed with [36] criterion by comparing the square root of AVE to all correlation coefficients. The chi-square statistic $\left(\chi^{2}\right)$, root mean square error of 
approximation (RMSEA), goodness of fit index (GFI), comparative fit index (CFI), normed fit index (NFI), Tucker-Lewis index (TLI), and standardized root mean square residual index (SRMR) fit indices were used to assess the fit of the measurement model. After the initial CFA was deployed, structural models were specified and tested with the CB-SEM and PLS-SEM methods.

An IBM AMOS 22 was used for the CB-SEM structural model. Data processing was implemented in the several stages advised in the literature (e.g., $[37,38])$. First, the model was specified according to the hypotheses, then parameters (loadings and structural paths) were estimated with the maximum likelihood (ML) procedure. In the third phase, the overall fit of the structural model was evaluated with several fit indices: $\chi^{2}$, RMSEA, GFI, CFI, NFI, and TLI. The model was evaluated according to the cut-off criteria suggested by $[39,40]$. The same procedure was used for the PLS-SEM approach using the Smart PLS 3 with the difference that only the NFI and SRMR were calculated for the overall model evaluation, as these are two commonly global goodness of fit measures used in PLS-SEM.

\subsection{Distribution of Data}

For all samples and variables that were entered into the analysis, the Kolmogorov-Smirnov test for normality was performed; for all variables the $p$ values were significant, meaning that the data were nonnormally distributed.

\section{Results}

\subsection{Dimensionality, Validity, and Reliability of the Scales}

The reliability of measurement scales for all samples was assessed within the scope of inner consistency with Cronbach's alpha coefficient [41]. Ref. [42] define that the indicators of highly reliable constructs should be connected, meaning they measure the same latent construct. The alpha coefficient of $\alpha \geq 0.80$ is marked as exemplary; the coefficient in the interval $0.70 \leq \alpha<0.80$ as very good; the interval $0.60 \leq \alpha<0.70$ as moderate; and smaller than 0.60 as barely acceptable [42]. Cronbach's alphas in Table 1 show that the scales were reliable for all measurement scales across all samples (see Section 2.5).

Table 1. Cronbach's alphas for different samples.

\begin{tabular}{cccccccc}
\hline Construct & $\begin{array}{c}\text { Alpha } \\
\text { Sample } \\
\mathbf{2 5}\end{array}$ & $\begin{array}{c}\text { Alpha } \\
\text { Sample } \\
\mathbf{5 0}\end{array}$ & $\begin{array}{c}\text { Alpha } \\
\text { Sample } \\
\mathbf{1 0 0}\end{array}$ & $\begin{array}{c}\text { Alpha } \\
\text { Sample } \\
\mathbf{2 5 0}\end{array}$ & $\begin{array}{c}\text { Alpha } \\
\text { Sample } \\
\mathbf{4 0 0}\end{array}$ & $\begin{array}{c}\text { Alpha } \\
\text { Sample } \\
\mathbf{5 0 0}\end{array}$ & $\begin{array}{c}\text { Alpha } \\
\text { Sample } \\
\mathbf{1 0 1 3}\end{array}$ \\
\hline Stress & 0.859 & 0.868 & 0.924 & 0.920 & 0.927 & 0.929 & 0.929 \\
Employee relations & 0.928 & 0.973 & 0.956 & 0.948 & 0.950 & 0.954 & 0.951 \\
Employee satisfaction & 0.899 & 0.903 & 0.908 & 0.909 & 0.905 & 0.898 & 0.896 \\
Employee motivation & 0.943 & 0.945 & 0.941 & 0.938 & 0.933 & 0.928 & 0.930 \\
\hline
\end{tabular}

In order to assess the proper dimensionality, reliability, and validity, CFA was performed using the CB-SEM on the whole database. Some of the items with low loadings on their latent variables or with high cross-loadings were excluded from the model. The final CB-SEM measurement model consisted of five indicators for stress, three indicators for employee relationships, five indicators for motivation, and three indicators for employee satisfaction. An overall fit assessment of the structural model yielded a significant chi-square value $\chi^{2}([97]=645.79 ; p<0.001)$, which indicated a nonperfect fit. However, according to [43], other fit indices should be used, since $\chi^{2}$ may be an inappropriate standard when researchers are dealing with a complex model and with a large sample size. The following fit indices were calculated for the measurement model: $\mathrm{RMSEA}=0.073, \mathrm{GFI}=0.924, \mathrm{NFI}=0.964, \mathrm{TLI}=0.962$, and $\mathrm{CFI}=0.969$. All indices were within the accepted boundaries as proposed by representative authors in the field $[39,40]$. The same variables were also used for constructing the PLS-SEM model.

All indicator loadings in the CB-SEM model were higher than 0.7 (Table 2) and statistically significant. In addition, the average variances extracted (AVE) were all higher than 0.7 , indicating the 
appropriate convergent validity. The composite reliability (CR) measures exceeded the suggested level of 0.6, suggesting a high reliability of the scales. Ref. [36] criterion was used to test for discriminant validity. As can be observed from Table 2, the square roots of AVE in a majority of cases were higher than the latent variable correlations. In some cases, this could not be supported, mainly due to high AVE values.

Table 2. Indicators loadings and latent variables composite reliabilities (CRs) and average variances extracted (AVEs) for the covariance-based structural equation modeling (CB-SEM) and the partial least squares structural equation modeling (PLS-SEM) models (calculated on the largest sample).

\begin{tabular}{|c|c|c|c|c|c|c|c|c|}
\hline \multirow{2}{*}{ Latent and Manifest Variables } & \multirow{2}{*}{ Mean } & \multirow{2}{*}{ Std. Dev. } & \multicolumn{3}{|c|}{ CB-SEM } & \multicolumn{3}{|c|}{ PLS-SEM } \\
\hline & & & Lambda & CR & AVE & Lambda & CR & AVE \\
\hline \multicolumn{9}{|l|}{ Stress } \\
\hline $\begin{array}{l}\text { Q1d: Due to stress in the workplace, I } \\
\text { feel a lack of energy, tiredness. }\end{array}$ & 3.25 & 1.010 & 0.794 & \multirow{5}{*}{0.931} & \multirow{5}{*}{0.731} & 0.843 & \multirow{5}{*}{0.947} & \multirow{5}{*}{0.780} \\
\hline $\begin{array}{l}\text { Q1e: Due to stress in the workplace, I } \\
\text { have problems with concentration. }\end{array}$ & 2.60 & 0.995 & 0.909 & & & 0.919 & & \\
\hline $\begin{array}{l}\text { Q1f: I feel the lack of my capacity in } \\
\text { performing my work tasks. }\end{array}$ & 2.75 & 1.042 & 0.920 & & & 0.924 & & \\
\hline Q1h: I'm irritable. & 2.69 & 1.069 & 0.856 & & & 0.886 & & \\
\hline $\begin{array}{l}\text { Q1j: Because of the large amount of } \\
\text { work, I need more rest during work. }\end{array}$ & 2.50 & 0.998 & 0.786 & & & 0.841 & & \\
\hline \multicolumn{9}{|l|}{ Employee relations } \\
\hline $\begin{array}{c}\text { Q6e: We cooperate very well with } \\
\text { colleagues in the performance of our } \\
\text { tasks. }\end{array}$ & 3.90 & 0.856 & 0.934 & \multirow{3}{*}{0.952} & \multirow{3}{*}{0.869} & 0.953 & \multirow{3}{*}{0.969} & \multirow{3}{*}{0.913} \\
\hline $\begin{array}{l}\text { Q6f: In our organization we appreciate } \\
\text { the work of our colleagues. }\end{array}$ & 4.12 & 0.804 & 0.920 & & & 0.953 & & \\
\hline $\begin{array}{l}\text { Q6h: Between employees prevail trust } \\
\text { and good cooperation. }\end{array}$ & 3.94 & 0.890 & 0.942 & & & 0.960 & & \\
\hline \multicolumn{9}{|l|}{ Employee satisfaction } \\
\hline $\begin{array}{l}\text { Q9a: At my workplace I am satisfied } \\
\text { with working hours and distribution of } \\
\text { work obligations. }\end{array}$ & 3.41 & 1.028 & 0.905 & \multirow{3}{*}{0.896} & \multirow{3}{*}{0.744} & 0.938 & \multirow{3}{*}{0.935} & \multirow{3}{*}{0.828} \\
\hline $\begin{array}{l}\text { Q9c: At my workplace I am satisfied } \\
\text { with flexible working hours. }\end{array}$ & 3.39 & .986 & 0.938 & & & 0.938 & & \\
\hline $\begin{array}{l}\text { Q9d: At my workplace I am satisfied } \\
\text { with the balance between work and } \\
\text { private life. }\end{array}$ & 3.78 & 1.012 & 0.730 & & & 0.851 & & \\
\hline \multicolumn{9}{|l|}{ Employee motivation } \\
\hline $\begin{array}{l}\text { Q8b: The employer motivates us with } \\
\text { possibility of cooperation with other } \\
\text { employees and with the distribution of } \\
\text { our work. }\end{array}$ & 3.69 & 0.916 & 0.890 & \multirow{5}{*}{0.936} & \multirow{5}{*}{0.746} & 0.907 & \multirow{5}{*}{0.951} & \multirow{5}{*}{0.794} \\
\hline $\begin{array}{l}\text { Q7h: The employer motivates us with } \\
\text { the possibility of advancement. }\end{array}$ & 3.23 & 1.086 & 0.774 & & & 0.913 & & \\
\hline $\begin{array}{l}\text { Q7f: For better performance at my } \\
\text { work I have the possibility of working } \\
\text { at my own pace. }\end{array}$ & 3.46 & 1.012 & 0.854 & & & 0.924 & & \\
\hline $\begin{array}{l}\text { Q7c: The employer motivates us with } \\
\text { the possibility of flexibility in the } \\
\text { workplace. }\end{array}$ & 3.46 & 0.966 & 0.905 & & & 0.884 & & \\
\hline $\begin{array}{l}\text { Q7b: In the company we are praised } \\
\text { for good work. }\end{array}$ & 3.21 & 1.271 & 0.890 & & & 0.825 & & \\
\hline
\end{tabular}

Similar tests were performed on the PLS-SEM model on the largest sample, only using the final structural model. As for the CB-SEM, loadings were all higher than 0.8, with AVE values higher than 0.7 and CR values higher than 0.9. In this case, Ref. [36] criterion was achieved in all cases (Table 3) since all square roots of AVE were higher than the latent variable correlations. 
Table 3. Square roots of the AVE and correlations among the latent variables for the CB-SEM and PLS-SEM models.

\begin{tabular}{|c|c|c|c|c|c|c|c|c|}
\hline & $\begin{array}{l}\text { Employee } \\
\text { Relations }\end{array}$ & Stress & $\begin{array}{c}\text { Employee } \\
\text { Motivation }\end{array}$ & $\begin{array}{c}\text { Employee } \\
\text { Satisfaction }\end{array}$ & $\begin{array}{l}\text { Employee } \\
\text { Relations }\end{array}$ & Stress & $\begin{array}{c}\text { Employee } \\
\text { Motivation }\end{array}$ & $\begin{array}{c}\text { Employee } \\
\text { Satisfaction }\end{array}$ \\
\hline Employee relations & $0.932 *$ & & & & 0.955 * & & & \\
\hline Stress & -0.708 & $0.855 *$ & & & -0.684 & $0.883 *$ & & \\
\hline $\begin{array}{l}\text { Employee } \\
\text { motivation }\end{array}$ & 0.905 & -0.741 & $0.863 *$ & & 0.854 & -0.702 & $0.891 *$ & \\
\hline $\begin{array}{c}\text { Employee } \\
\text { satisfaction }\end{array}$ & 0.874 & -0.707 & 0.944 & $0.863 *$ & 0.812 & -0.659 & 0.869 & 0.910 * \\
\hline
\end{tabular}

According to the proposed hypotheses, structural models were tested with CB-SEM and PLS-SEM on seven samples with 25, 50, 100, 250, 400, 500, and 1013 employees.

\subsection{CB-SEM and PLS-SEM Results}

The CB-SEM and PLS-SEM results are presented in Tables 4 and 5. For CB-SEM analysis, the model fit was assessed with $\chi^{2}(\mathrm{df})$, RMSEA, GFI, NFI, TLI, and CFI fit indices. $\chi^{2}$ was statistically significant for all samples, but, as already mentioned, this is not always the most appropriate fit index. As can be seen from Table 4, the GFI and NFI for the 25 and 50 employee samples were lower than 0.9 , indicating a bad fit for the model. The GFI fit indices were lower than 0.9 for the 100 and 250 employee samples. However, other fit indices were within the suggested intervals meeting the suggested thresholds.

Table 4. Fit indices for CB-SEM and PLS-SEM.

\begin{tabular}{cccccccc}
\hline Method & \multicolumn{3}{c}{ CB-SEM } & \multicolumn{2}{c}{ PLS-SEM } \\
\hline Sample Size & GFI & NFI & TLI & CFI & RMSEA & NFI & SRMR \\
\hline 25 & 0.612 & 0.832 & 0.902 & 0.920 & 0.155 & 0.685 & 0.081 \\
50 & 0.727 & 0.832 & 0.902 & 0.920 & 0.122 & 0.797 & 0.075 \\
100 & 0.839 & 0.914 & 0.954 & 0.962 & 0.085 & 0.879 & 0.055 \\
250 & 0.870 & 0.938 & 0.949 & 0.958 & 0.088 & 0.901 & 0.058 \\
400 & 0.895 & 0.952 & 0.961 & 0.968 & 0.076 & 0.912 & 0.056 \\
500 & 0.897 & 0.952 & 0.955 & 0.963 & 0.082 & 0.910 & 0.055 \\
1013 & 0.919 & 0.963 & 0.961 & 0.968 & 0.076 & 0.921 & 0.054 \\
\hline
\end{tabular}

Abbreviations: GFI—goodness of fit index, NFI—normed fit index, TLI—Tucker-Lewis index, CFI—comparative fit index, RMSEA — root mean square error of approximation, and SRMR—standardized root mean square residual index.

Table 5. Standardized regression paths for CB-SEM and PLS-SEM.

\begin{tabular}{|c|c|c|c|c|c|c|c|c|c|c|}
\hline \multirow{2}{*}{$\begin{array}{c}\text { Hypothesis } \\
\text { Method }\end{array}$} & \multicolumn{2}{|c|}{ H1 } & \multicolumn{2}{|c|}{ H2 } & \multicolumn{2}{|c|}{ H3 } & \multicolumn{2}{|c|}{ H4 } & \multicolumn{2}{|c|}{ H5 } \\
\hline & CB-SEM & PLS-SEM & CB-SEM & PLS-SEM & CB-SEM & PLS-SEM & CB-SEM & PLS-SEM & CB-SEM & PLS-SEM \\
\hline $\begin{array}{l}\text { Sample } \\
\text { Size }\end{array}$ & \multicolumn{2}{|c|}{$\begin{array}{c}\text { Stress -> } \\
\text { Employee Relations }\end{array}$} & \multicolumn{2}{|c|}{$\begin{array}{c}\text { Stress -> } \\
\text { Employee Satisfaction }\end{array}$} & \multicolumn{2}{|c|}{$\begin{array}{l}\text { Employee Relations -> } \\
\text { Employee Satisfaction }\end{array}$} & \multicolumn{2}{|c|}{$\begin{array}{l}\text { Employee Relations -> } \\
\text { Employee Motivation }\end{array}$} & \multicolumn{2}{|c|}{$\begin{array}{c}\text { Employee Satisfaction -> } \\
\text { Employee Motivation }\end{array}$} \\
\hline 25 & $\begin{array}{c}-0.809 \\
(p<0.01)\end{array}$ & $\begin{array}{c}-0.677 \\
(p<0.01)\end{array}$ & Non-significant & Non-significant & $\begin{array}{c}0.757 \\
(p<0.01)\end{array}$ & $\begin{array}{c}0.611 \\
(p<0.01)\end{array}$ & $\begin{array}{c}0.688 \\
(p<0.01)\end{array}$ & $\begin{array}{c}0.564 \\
(p<0.01)\end{array}$ & $\begin{array}{c}0.344 \\
(p<0.01)\end{array}$ & $\begin{array}{c}0.447 \\
(p<0.01)\end{array}$ \\
\hline 50 & $\begin{array}{c}-0.655 \\
(p<0.01)\end{array}$ & $\begin{array}{c}-0.610 \\
(p<0.01)\end{array}$ & Non-significant & Non-significant & $\begin{array}{c}0.835 \\
(p<0.01)\end{array}$ & $\begin{array}{c}0.714 \\
(p<0.01)\end{array}$ & $\begin{array}{c}0.562 \\
(p<0.01)\end{array}$ & $\begin{array}{c}0.478 \\
(p<0.01)\end{array}$ & $\begin{array}{c}0.429 \\
(p<0.01)\end{array}$ & $\begin{array}{c}0.508 \\
(p<0.01)\end{array}$ \\
\hline 100 & $\begin{array}{c}-0.790 \\
(p<0.01)\end{array}$ & $\begin{array}{c}-0.760 \\
(p<0.01)\end{array}$ & Non-significant & Non-significant & $\begin{array}{c}0.807 \\
(p<0.01)\end{array}$ & $\begin{array}{c}0.738 \\
(p<0.01)\end{array}$ & $\begin{array}{c}0.464 \\
(p<0.01)\end{array}$ & $\begin{array}{c}0.525 \\
(p<0.01)\end{array}$ & $\begin{array}{c}0.521 \\
(p<0.01)\end{array}$ & $\begin{array}{c}0.426 \\
(p<0.01)\end{array}$ \\
\hline 250 & $\begin{array}{c}-0.726 \\
(p<0.01)\end{array}$ & $\begin{array}{c}-0.691 \\
(p<0.01)\end{array}$ & $\begin{array}{c}-0.158 \\
(p<0.01)\end{array}$ & $\begin{array}{c}-0.156 \\
(p<0.01)\end{array}$ & $\begin{array}{c}0.778 \\
(p<0.01)\end{array}$ & $\begin{array}{c}0.725 \\
(p<0.01)\end{array}$ & $\begin{array}{c}0.355 \\
(p<0.01)\end{array}$ & $\begin{array}{c}0.443 \\
(p<0.01)\end{array}$ & $\begin{array}{c}0.638 \\
(p<0.01)\end{array}$ & $\begin{array}{c}0.518 \\
(p<0.01)\end{array}$ \\
\hline 400 & $\begin{array}{c}-0.713 \\
(p<0.01)\end{array}$ & $\begin{array}{c}-0.680 \\
(p<0.01)\end{array}$ & $\begin{array}{c}-0.174 \\
(p<0.01)\end{array}$ & $\begin{array}{c}-0.172 \\
(p<0.01)\end{array}$ & $\begin{array}{c}0.763 \\
(p<0.01)\end{array}$ & $\begin{array}{c}0.709 \\
(p<0.01)\end{array}$ & $\begin{array}{c}0.331 \\
(p<0.01)\end{array}$ & $\begin{array}{c}0.427 \\
(p<0.01)\end{array}$ & $\begin{array}{c}0.661 \\
(p<0.01)\end{array}$ & $\begin{array}{c}0.531 \\
(p<0.01)\end{array}$ \\
\hline 500 & $\begin{array}{c}-0.718 \\
(p<0.01)\end{array}$ & $\begin{array}{c}-0.696 \\
(p<0.01)\end{array}$ & $\begin{array}{c}-0.179 \\
(p<0.01)\end{array}$ & $\begin{array}{c}-0.201 \\
(p<0.01)\end{array}$ & $\begin{array}{c}0.754 \\
(p<0.01)\end{array}$ & $\begin{array}{c}0.676 \\
(p<0.01)\end{array}$ & $\begin{array}{c}0.371 \\
(p<0.01)\end{array}$ & $\begin{array}{c}0.471 \\
(p<0.01)\end{array}$ & $\begin{array}{c}0.613 \\
(p<0.01)\end{array}$ & $\begin{array}{c}0.474 \\
(p<0.01)\end{array}$ \\
\hline 1013 & $\begin{array}{c}-0.713 \\
(p<0.01)\end{array}$ & $\begin{array}{c}-0.684 \\
(p<0.01)\end{array}$ & $\begin{array}{c}-0.192 \\
(p<0.01)\end{array}$ & $\begin{array}{c}-0.195 \\
(p<0.01)\end{array}$ & $\begin{array}{c}0.738 \\
(p<0.01)\end{array}$ & $\begin{array}{c}0.678 \\
(p<0.01)\end{array}$ & $\begin{array}{c}0.329 \\
(p<0.01)\end{array}$ & $\begin{array}{c}0.436 \\
(p<0.01)\end{array}$ & $\begin{array}{c}0.659 \\
(p<0.01)\end{array}$ & $\begin{array}{c}0.515 \\
(p<0.01)\end{array}$ \\
\hline
\end{tabular}

Since it is not common to calculate as many fit indices in PLS-SEM as in CB-SEM, only NFI and the SRMR index were used in this case (Table 4). For samples larger than 250, NFI reached the suggested 
threshold of 0.9 , while for the smaller samples $(25,50,100)$ it was lower. SRMR for all cases was close or lower than 0.08 . $R^{2}$ values for all endogenous variables (employee relations, employee motivation, and employee satisfaction) for all samples were larger than 0.4.

As can be observed from Table 5, the results acquired with both methods showed that stress had a negative impact on employee relationships. The relationship was strong, negative, and statistically significant. The impact of stress on employee satisfaction was negative. This relationship was much weaker and statistically significant for larger samples, but not for the samples of 25, 50, and 100. In these cases, the relationships were non-significant. Employee relations had a strong and statistically significant impact on satisfaction and a moderately significant impact on employee motivation. The impact of satisfaction on employee motivation was strong and statistically significant.

\subsection{Final Results and Hypotheses Testing}

Concerning the hypotheses, the results were identical for the CB-SEM and the PLS-SEM models. Stress had a strong negative impact on employee relations, meaning that hypothesis $\mathrm{H} 1$ was confirmed for all samples. This was consistent with the findings of $[14-16,20,21,44,45]$ in which the authors found that a higher level of occupational stress causes a lower level of employee satisfaction and also causes poor relationships among employees.

The relationship between stress and employee relations was weak and statistically insignificant for smaller samples (sample sizes of 25,50 , and 100), but significant for larger samples. The hypothesis $\mathrm{H} 2$, therefore, could only be confirmed for larger samples. However, since stress decreases attention, concentration, and judgment skills, it can also potentially directly influence employee satisfaction. Hypothesis $\mathrm{H} 3$ was confirmed since the impact of employee relations on satisfaction was strong and statistically significant. It must be stressed that this relationship was one of the strongest in our model. Similar evidence is also provided in studies by $[23,25,26]$.

Employee relations had a positive and significant impact on motivation. Therefore, the hypothesis H4 was also confirmed for all samples. Employee relations seemed to be specifically important in achieving satisfaction and could also have a mediating influence of stress on satisfaction. This is in accordance with previous studies by [14,21-24]. Finally, satisfaction was a significant predictor of employee motivation. This was once again supported for all samples with both methods, confirming H5.

\section{Discussion}

The results showed that stress had a strong and negative impact on employee relationships and also had a negative impact on employee satisfaction. The working environment, such as having poor working relationships with colleagues and poor management styles, can be stressful. According to [44], very stressful organizational policies can include long working hours, job insecurity, inadequate training, an inadequate salary, and a lack of career prospects in the company. Ref. [46] explain that occupational stress is linked to employee performance. According to [47], stress decreases attention, concentration, and decision-making and judgment skills. Refs. [44,45] summarize that a strong inverse relationship was found between occupational stress and employees' quality of working life, morale, motivation, work satisfaction, and organizational commitment. Refs. [44,48] found that all age-diverse employees feel less stressed when they feel trusted, respected, and supported in the workplace. While all of them suffer when these elements are missing, these elements may be especially important for older employees. Ref. [49] reports stress levels also increase with age. Those who have a positive relationship with their colleagues and employers are more satisfied, motivated, and work more efficiently. Additionally, effective and positive employee relations will impact employee engagement, thus resulting in better company performance. Thus, healthy employee relations promote a positive workplace in which employees feel happy, satisfied, and engaged at work [50]. Further, Ref. [22] assert that the benefits of good employee relations include a higher level of innovation and creativity in the workplace. According to our study, employee relations had a strong and positive impact on satisfaction and a positive impact on employee motivation, which is in line with [14,21-24], suggesting 
that good relationships in the workplace led to an increased level of satisfaction and motivation among the employees in the workplace. Furthermore, we showed that satisfaction had a strong and positive impact on employee motivation. Motivated employees can lead to an increase in productivity, more innovation, and higher levels of competition for an organization [51].

On the other hand, age-diverse employees have different needs, values, goals, intentions, and expectations [15], therefore, it is important for every company to understand the factors that affect the motivation of age-diverse workers [52]. For example, older employees are motivated by autonomy at work, flexibility in the workplace, and good interpersonal relationships in the workplace. Younger staff are more motivated by a higher salary and possibilities for advancement $[53,54]$. Ref. [55] emphasize that it is crucial to understand age-related changes in work satisfaction and motivation. According to [56], maintaining a high level of motivation at different ages and for older employees, in particular, is a prerequisite for successful management when dealing with changes in work capabilities. There are also differences between older and younger employees in their satisfaction in the workplace. For example, Ref. [57] found that those who are older are more satisfied with their jobs than younger ones.

From an organizational point of view, our conclusions highlight the importance of the relationships between older employee stress, motivation, satisfaction, and relationships in the workplace. These are especially important for older employees. For them, autonomy and flexibility in the workplace and feeling supported by their employers help them deal with the psychological and physical changes of aging. While younger workers are more focused on learning skills and advancing careers, older employees are more interested in emotional needs. They also find more value at work through meaningful interactions with their colleagues and in mentoring roles with younger coworkers. Additionally, older employees have lower levels of stress and higher levels of satisfaction when they have more autonomy in the workplace, as well as good relationships with coworkers and employers. Feeling that they are respected and treated fairly is important for those who are faced with discrimination and stereotypes in the workplace, which leads to lower levels of work satisfaction and motivation. Due to the existence of stereotypes and prejudices against older employees, they feel less important for the company, therefore, their working capacity could be reduced. The poor management of diversity can have negative consequences, for example, the reduction of skills, employee motivation, and satisfaction, which means less efficiency. If the company does not take the existence and importance of the diversity in the workforce into account, it may come to a situation in which the company and the employees will not achieve their goals or exploit their potential. The basic condition for successful management in the organization is reflected by the support for high satisfaction and motivation of all workers, at different ages. Positive changes for older employees in the workplace will increase work performance. However, in order to achieve a high level of employee satisfaction, motivation, and productivity, management needs to encourage a positive and healthy work environment.

Generally, our assumption that the PLS-SEM method is more adequate to analyze the relationships between the human resource variables in the settings where the researchers do not have the access to a larger sample of employees could not be supported. Since the results were similar, we can speculate that the CB-SEM has some advantages in comparison to PLS-SEM. First, in our case, the analytical procedures were used for testing the theory but adopted for the older employee context. Second, Ref. [58] state that major shortcomings of the PLS-SEM model in comparison with the CB-SEM model are the adherence to the common factor model, limited simulation designs, and over-stretched generalizations of their findings. This view was not shared by [59], who show that PLS does offer advantages for exploratory research in settings where the common factor model does not hold. Our research showed that researchers should be encouraged to use both techniques, even though CB-SEM methods have had a long tradition in management and marketing research since both fields heavily rely on psychometric measurement.

Our sample was limited only to older employees in Slovenian medium- and large-sized companies. A further limitation is related to only considering stress, motivation, satisfaction, and employee relations in the workplace. There are several other factors that could additionally influence those four variables, 
such as employee communication in the workplace, employee well-being in the workplace, employee work engagement, etc.

For future research, it should be recommended to add other constructs in the area of older or younger employees and analyzing them with different structural equation modeling techniques, also including non-linear approaches.

An additional limitation concerning the interpretation of the results that should be mentioned is the notion that for all SEM or even other statistical methods, situations could be found by the researchers in which such methods do not work appropriately. This can be due to a small sample size, parameter values close to critical boundaries, distributions, or any combination of these [59].

\section{Conclusions}

In this paper, the relationships among older employee stress, motivation, satisfaction, and relationships in the workplace using two different approaches (CB-SEM and PLS-SEM) and different sample sizes were investigated. The results on the larger samples were quite robust since they were confirmed with two different SEM methods. It was revealed that stress had a strong and negative impact on employee relationships and also had a negative impact on employee satisfaction.

Concerning the model fit indices, both methods proved to be sample sensitive. The normed fit index (NFI) was not in the suggested intervals for samples under 100, regardless of the SEM method used. For the CB-SEM, the GFI was under the suggested threshold of 0.9, except for the largest sample, but this index is known to be highly sensitive to small sample sizes [60]. Additionally, the RMSEA proved to be affected by the same issue for samples smaller than 400 , since it was higher than the recommended threshold of 0.08 or 0.07 , which is recognized as indicative of good fit $[39,61]$, meaning that strictly by the rule, in some cases, the model should be rejected.

Comparing the two analytical procedures did not result in any major differences. Although rare authors suggest using the PLS-SEM method when sample sizes are small and when the data are non-normally distributed in order to get more accurate results, this was not the case concerning our research. [5], for example, reports that under a normal distribution, CB-SEM failed to estimate correctly the path estimates for small sample sizes and that PLS-SEM has a slight advantage in comparison to CB-SEM with the ability to report medians nearing the true values for small sizes. In our case, the PLS-SEM method and CB-SEM method provided the same values for the paths between stress and employee relations, namely they were insignificant for samples smaller than 100 . In contrast, estimations of path coefficients on the larger samples were negative and statistically significant.

Author Contributions: Conceptualization, M.R., P.T. and B.M.; Methodology, M.R., P.T. and B.M.; Software, B.M.; Validation, B.M.; Formal Analysis, B.M., P.T. and M.R.; Investigation, M.R.; Resources, M.R., P.T. and B.M.; Writing-Original Draft Preparation, M.R., P.T. and B.M.; Writing-Review \& Editing, M.R., P.T. and B.M. All authors have read and agreed to the published version of the manuscript.

Funding: The authors acknowledge the project "Entrepreneurship for Innovative Society", P5-0023, was financially supported by the Slovenian Research Agency.

Conflicts of Interest: The authors declare no conflict of interest.

\section{References}

1. Lim, D.H.; Jeong, S.; Yoo, S.; Yoo, M.H. Older workers' education andearnings among OECD countries. Eur. J. Train. Dev. 2018, 42, 170-190. [CrossRef]

2. Gefen, D.; Straub, D.; Boudreau, M.C. Structural Equation Modeling and Regression: Guidelines for research Practice. Commun. Assoc. Inf. Syst. 2000, 4, 7. [CrossRef]

3. Hair, J.F.; Hult, G.T.M.; Ringle, C.M.; Sarstedt, M. A Primer on Partial Least Squares Structural Equation Modeling (PLS-SEM); Sage: Thousand Oaks, CA, USA, 2016.

4. Garson, G.D. Partial Least Squares: Regression and Structural Equation Models; Statistical Associates Publishers: Asheboro, NC, USA, 2016. 
5. Jannoo, Z.; Yap, B.W.; Auchoybur, N.; Lazim, M.A. The Effect of Nonnormality on CB-SEM and PLS-SEM Path Estimates. Int. J. Math. Comput. Sci. 2014, 8, 285-291.

6. Yang, T.; Shen, Y.M.; Zhu, M.; Liu, Y.; Deng, J.; Chen, Q.; See, L.C. Effects of Co-Worker and Supervisor Support on Job Stress and Presenteeism in an Aging Workforce: A Structural Equation Modelling Approach. Int. J. Environ. Res. Public Health 2016, 13, 72. [CrossRef]

7. Valaei, N.; Jiroudi, S. Job satisfaction and job performance in the media industry. Asia Pac. J. Mark. Logist. 2016, 28, 984-1014. [CrossRef]

8. Egan, T.; Yang, B.; Bartlett, K. The effects of organizational learning culture and job satisfaction on motivation to transfer learning and intention to sharing knowledge. Hum. Resour. Dev. Q. 2004, 15, 279-301. [CrossRef]

9. Gonzalez, J.; de Boeck, P.; Tuerlinckx, F. A double structure structural equation model for three-mode data. Psychol. Methods 2008, 13, 337-353. [CrossRef]

10. Cheung, G.W. Testing equivalence in the structure, means, and variances of higher-order constructs with structural equation modeling. Organ. Res. Methods 2008, 11, 593-613. [CrossRef]

11. Tarka, P. An overview of structural equation modeling: Its beginnings, historical development, usefulness and controversies in the social sciences. Qual. Quant. 2017, 52, 313-354. [CrossRef]

12. Hair, J.F.; Ringle, C.M.; Sarstedt, M. PLS-SEM: Indeed a Silver Bullet. J. Mark. Theory Pract. 2011, 19, $139-151$. [CrossRef]

13. Williams, L.J.; Vandenberg, R.J.; Edwards, J.R. Structural equation modeling in management research: A guide for improved analysis. Acad. Manag. Ann. 2009, 3, 543-604. [CrossRef]

14. Ajayi, S. Effect of Stress on Employee Performance and Job Satisfaction: A Case Study of Nigerian Banking Industry. 2018. Available online: https://ssrn.com/abstract=3160620 (accessed on 8 January 2020).

15. Armstrong, M. Human Resource Management Practice; Kogan Page Limited: London, UK, 2014.

16. Venkataraman, P.S.; Ganapathi, R. A Study of Job Stress on Job Satisfaction among the Employees of Small Scale Industries. J. Bus. Manag. 2013, 13, 18-22. [CrossRef]

17. Gershon, R.R.; Barocas, B.; Canton, A.N.; Li, X.; Vlahov, D. Mental, physical, and behavioral outcomes associated with perceived work stress in police officers. Crim. Justice Behav. 2000, 36, 275-289. [CrossRef]

18. Machin, M.A.; Fogarty, G.J.; Albion, M.J. The relationship of work support and work demands to individual outcomes and absenteeism of rural nurses. Int. J. Rural Psychol. 2004, 4, 1-13.

19. Mosadeghrad, A.M. Occupational stress and turnover intention: Implications for nursing management. Int. J. Health Policy Manag. 2013, 1, 179-186. [CrossRef]

20. Chandraiah, K.; Agrawal, S.C.; Marimuthu, P.; Manoharan, N. Job Satisfaction among Managers. Indian J. Occup. Environ. Med. 2003, 7, 125-134.

21. Lindfors, P.; Hansen, N. Control dimensions, job demands and job satisfaction: Does ownership matter? Int. J. Workplace Health Manag. 2018, 11, 305-318. [CrossRef]

22. Ford, D. Managing Business Relations; Wiley: New York, NY, USA, 2011.

23. Kian, T.S.; Yusoff, W.F.W.; Rajah, S. Job satisfaction and motivation: What are the difference among these two. Eur. J. Bus. Soc. Sci. 2014, 3, 94-102.

24. Pang, K.; Lu, C.S. Organizational motivation, employee job satisfaction and organizational performance: An empirical study of container shipping companies in Taiwan. Marit. Bus. Rev. 2018, 3, 36-52. [CrossRef]

25. Oni-Ojo, E.E.; Salau, O.P.; Dirisu, J.F.; Waribo, Y. Incentives and job satisfaction: Its implications for competitive positioning and organizational survival in Nigerian manufacturing industries. Am. J. Manag. 2015, 15, 74-87.

26. Adamy, A.; Adamy, M. The Effect of Job Satisfaction and Work Motivation on Organizational Commitment and Organizational Citizenship Behavior in BNI in the Working Area of Bank Indonesia Lhokseumawe. 2018. Available online: https://www.emerald.com/insight/content/doi/10.1108/978-1-78756-793-1-00063/full/html (accessed on 5 January 2020).

27. Bloch, O. Creating motivation and engagement through values. Hum. Resour. Manag. 2015, 64, 14-20.

28. Gunnigle, P.; Turner, T.; Morley, M. Strategic integration and employee relations: The impact of managerial styles. Empl. Relat. 1998, 20, 115-131. [CrossRef]

29. Hayday. Questions to Measure Commitment and Job Satisfaction. 2003. Available online: https://www. employment-studies.co.uk/system/files/resources/files/mp19.pdf (accessed on 11 January 2020).

30. Henseler, J.; Ringle, C.M.; Sinkovics, R.R. The use of partial least squares path modeling in international marketing. Adv. Int. Mark. 2009, 20, 277-320. 
31. Becker, J.M.; Rai, A.; Rigdon, E.E. Predictive Validity and Formative Measurement in Structural Equation Modeling: Embracing Practical Relevance. 2013. Available online: https://scholarworks.gsu.edu/cgi/ viewcontent.cgi?referer=https://www.google.si/\&httpsredir=1\&article=1000\&context=marketing_facpub (accessed on 12 January 2020).

32. Rigdon, E.E. Rethinking partial least squares path modeling: In praise of simple methods. J. Long Range Plan. 2012, 45, 341-358. [CrossRef]

33. Hair, J.F.; Hult, G.T.M.; Ringle, C.M.; Sarstedt, M. A Primer on Partial Least Squares Structural Equation Modeling (PLS-SEM); Sage: Thousand Oaks, CA, USA, 2014.

34. Bagozzi, R.; Yi, Y. Specification, evaluation, and interpretation of structural equation models. J. Acad. Mark. Sci. 2012, 40, 8-34. [CrossRef]

35. Reinartz, W.J.; Haenlein, M.; Henseler, J. An Empirical Comparison of the Efficacy of Covariance-Based and Variance-Based SEM. Int. J. Market. Res. 2009, 26, 332-344. [CrossRef]

36. Fornell, C.; Larcker, D.F. Evaluating structural equation models with unobservable variables and measurement error. J. Mark. Res. 1981, 18, 39-50. [CrossRef]

37. Anderson, J.C.; Gerbing, D.W. Structural equation modeling in practice: A review and recommended two-step approach. Psychol. Bull. 1988, 103, 411-442. [CrossRef]

38. Ullman, J.B.; Bentler, P.M. Structural equation modeling. Handb. Psychol. 2003, 2, 607-634.

39. Hu, L.T.; Bentler, P.M. Cutoff criteria for fit indexes in covariance structure analysis: Conventional criteria versus new alternatives. Struct. Equ. Modeling Multidiscip. J. 1999, 6, 1-55. [CrossRef]

40. MacCallum, R.C.; Browne, M.W.; Sugawara, H.M. Power analysis and determination of sample size for covariance structure modeling. Psychol. Methods 1996, 1, 130-149. [CrossRef]

41. Chronbach, L.J. Coefficient alpha and the internal structure of tests. Psychometrika 1951, 16, $297-334$. [CrossRef]

42. Churchill, G.A.; Brown, T.J. Basic Marketing Research; Thomson: Mason, OH, USA, 2004.

43. Bollen, K.A. Structural Equations with Latent Variables; Wiley: New York, NY, USA, 1989.

44. Mosadeghrad, A.M. Occupational stress and its consequences: Implications for health policy and management. Leadersh. Health Serv. 2014, 27, 224-239. [CrossRef]

45. Mosadeghrad, A.M.; Ferlie, E.; Rosenberg, D. A study of relationship between job stress, quality of working life and turnover intention among hospital employees. Health Serv. Manag. Res. J. 2011, 24, 170-181. [CrossRef]

46. Abualrub, R.F.; AL-Zaru, I.M. Job stress, recognition, job performance and intention to stay at work among Jordanian hospital nurses. J. Nurs. Manag. 2008, 16, 227-236. [CrossRef]

47. Shapiro, S.L.; Astin, J.A.; Bishop, S.R.; Cordova, M. Mindfulness-based stress reduction for health care professionals: Results from a randomized trial. Int. J. Stress Manag. 2005, 12, 164-176. [CrossRef]

48. Cheung, F.; Wu, A.M.S. Older workers' successful aging and intention to stay. J. Manag. Psychol. 2013, 28, 645-660. [CrossRef]

49. Scheibe, S.; Zacher, H. A Lifespan Perspective on Emotion Regulation, Stress, and Well-being in the Workplace. Res. Occup. Stress Well Being 2013, 11, 163-193.

50. Anitha, J. Determinants of employee engagement and their impact on employee performance. Int. J. Product. Perform. Manag. 2014, 63, 308-323.

51. Bhatti, O.K.; Aslam, U.S.; Hassan, A.; Sulaiman, M. Employee motivation an Islamic perspective. Humanomics 2016, 32, 33-47. [CrossRef]

52. Sulaiman, M.; Ahmad, K.; BaraaSbaih, B.; Kamil, M.N. The perspective of Muslim employees towards motivation and career success. J. Soc. Sci. Humanit. 2014, 9, 45-62.

53. Kooij, D.; de Lange, A.; Jansen, P.; Dikkers, J. Older workers motivation to continue to work: Five meanings of age. J. Manag. Psychol. 2008, 23, 364-394. [CrossRef]

54. Kooij, D.; De Lange, A.; Jansen, P.; Kanfer, R.; Dikkers, J. Age and work-related motives: Results of a meta-analysis. J. Organ. Behav. 2011, 32, 197-225. [CrossRef]

55. Stamov-Roßnagel, C.; Biemann, T. Ageing and work motivation: A task-level perspective. J. Manag. Psychol. 2012, 27, 459-478. [CrossRef]

56. Stamov-Roßnagel, C.; Hertel, G. Older workers motivation: Against the myth of general decline. Manag. Decis. 2010, 48, 894-906. [CrossRef] 
57. Chileshe, N.; Haupt, T.C. The effect of age on the job satisfaction of construction workers. J. Eng. Des. Technol. 2010, 8, 107-118. [CrossRef]

58. Rönkko, M.; Evermann, J. A critical examination of common beliefs about partial least squares pathmodeling. Organ. Res. Methods 2013, 16, 425-448. [CrossRef]

59. Henseler, J.; Dijkstra, T.K.; Sarstedt, M.; Ringle, C.M.; Diamantopoulos, A.; Straub, D.W.; Calantone, R.J. Common beliefs and reality about PLS: Comments on Rönkkö and Evermann. Organ. Res. Methods 2013, 17, 182-209. [CrossRef]

60. Shevlin, M.; Miles, J. Effects of sample size, model specification and factor loadings on the GFI in confirmatory factor analysis. Personal. Individ. Differ. 1998, 25, 85-90. [CrossRef]

61. Steiger, J.H. Understanding the limitations of global fit assessment in structural equation modeling. Personal. Individ. Differ. 2007, 42, 893-898. [CrossRef]

(C) 2020 by the authors. Licensee MDPI, Basel, Switzerland. This article is an open access article distributed under the terms and conditions of the Creative Commons Attribution (CC BY) license (http://creativecommons.org/licenses/by/4.0/). 